\title{
Investigating the Biological Activity of Some Useful Heterocycles
}

\author{
Marthe C. D. Fotsing, Celine Bonneaud, Nicolette Niemann, Vuyo Mavumengwana, \\ and Derek T. Ndinteh
}

\begin{abstract}
A series of aryl and alkyl pyrimido[1,2-a]benzimidazole derivatives was synthesized according to published procedures. All synthesized compounds were fully characterized by spectral and microanalytical data. The compounds $(\mathbf{1 a}, \mathbf{1 b}, \mathbf{2 a}, \mathbf{2} \mathbf{b}$ and $\mathbf{2 c})$ were screened for their antimicrobial activity against Gram-positive and Gram-negative bacteria and only compound $\mathbf{2 b}$ showed moderate to good activity with respect to minimum inhibitory concentrations and by disc diffusion assays. Apart from Proteus vulgaris, which showed resistance against all the compounds, Enterobacter cloacae, Escherichia coli and Proteus mirabilis were the most susceptible Gram-negative bacteria with MIC of $1 \mu \mathrm{g} / \mathrm{ml}, 4 \mu \mathrm{g} / \mathrm{ml}$ and $2 \mu \mathrm{g} / \mathrm{ml}$ respectively. On the other hand, Staphylococcus epidermis, Staphylococcus aureus, Bacillus cereus, Bacillus subtilis, Enterococcus faecalis and Mycobacterium smegmatis all showed susceptibility with MIC's of $15.62 \mu \mathrm{g} / \mathrm{ml}, 31.25 \mu \mathrm{g} / \mathrm{ml}, 62.5 \mu \mathrm{g} / \mathrm{ml}, 3.9$ $\mu \mathrm{g} / \mathrm{ml}, 62.5 \mu \mathrm{g} / \mathrm{ml}$ and $7.81 \mu \mathrm{g} / \mathrm{ml}$ respectively.
\end{abstract}

Keywords-2-aminobenzimidazole, antibacterial, double Michael addition, pyrimido[1, 2-a] benzimidazole,.

\section{INTRODUCTION}

Although antibiotics have long been part of our arsenal against microbial pathogens, recent discoveries point to a rather disturbing outlook with regards to antibiotic resistance, particularly with notorious pathogens like methicillin-resistant Staphylococcus aureus (MRSA) and Mycobacterium tuberculosis (Mtb). Moreover, through the misuse, mismanagement and delay in the diagnosis of TB, the disease can potentially progress to multidrug-resistant tuberculosis (MDR-TB) and extensively drug-resistant tuberculosis (XDR TB) [1]. To complicate matters, only a handful of antimicrobials have been developed in the last couple of years and passed stringent clinical trials for public use. As such, drug resistance (even for microbial infections that were not viewed as

Manuscript received 20 June 2017. This work was supported by the National Research Foundation (NRF) under Grant 99704 and the University of Johannesburg. The authors are also indebted to the 2015 AGNES grant to junior researchers for their financial support.

M. C. D. Fotsing is a postdoctoral research fellow in the Department of Applied Chemistry at the University of Johannesburg. (E-mail: carinemarthe@gmail.com).

C. Bonneaud is currently a $\mathrm{PhD}$ student (e-mail: celine.bonneaud@gmail.com).

N. Niemann was a postdoctoral research fellow at the University of Johannesburg in the Department of Food and Biotechnology

V. Mavumengwana is a senior lecturer in the Department of Food and Biotechnology at the University of Johannesburg.

Derek Tantoh Ndinteh is a senior lecturer in the department of Applied Chemistry at the University of Johannesburg (E-mail: dndinteh@uj.ac.za). problematic anymore) is on the increase. Novel efficacious antibiotics with less or no side effects are therefore required to add on and update existing therapies. A comprehensive review by Cantas et al [2] discusses a number of issues and advances with regard to the development of various antimicrobials (semi-synthetic, synthetic and natural products and their respective derivatives) which show a variety of bioactive profiles, ease of synthesis or isolation procedures and future prospects with respect to combating drug resistance.

As far as antimicrobial synthetic compounds are concerned, the last couple of years have witnessed the utility of 2-aminobenzimidazoles and their derivatives in the fight against bacterial pathogens and a variety of other non-communicable diseases. Commercially available drugs like omeprazole, candesartan, bendamustine, benoxaprofen (despite its suspension in the 80's) targeting diseases such as ulcers, hypertension, cancer and inflammation respectively, possess the benzimadazole nucleus [3].

While Shaaban et al managed to demonstrate that a pyrimido[1,2-a]benzimidazole derivative has weak anti-inflammatory activity [4], Shah et al synthesized a series of 1,4-dihydro pyrimido[1,2-a]benzimidazole derivatives which exhibited modest activity against $S$. aureus, $S$. epidermidis, $E$. coli, P. aeruginosa and the fungus Aspergillus niger [5]. Since a number of compounds bearing the benzimidazole scaffold have been shown to possess interestingly diverse biological activities, we were interested in evaluating the antibacterial activity of a series of pyrimido[1,2-a]benzimidazole derivatives so as to explore the significance of their aryl and alkyl moieties.

\section{MATERIALS AND METHODS}

\section{A. Reagents}

All reagents used were of analytical grade and unless otherwise mentioned, they were all purchased from Sigma Aldrich. The bacterial strains were obtained from Davies diagnostics.

\section{B. Bacteria}

Twelve bacterial strains (Gram-positive bacteria: Bacillus cereus (ATCC10876), B. subtilis (ATCC19659), Enterococcus faecalis (ATCC13047), Mycobacterium smegmatis $\left(\mathrm{MC}^{2} 155\right.$, kind gift from the Centre of Excellence in Biomedical TB Research, University of the Witwatersrand), Staphylococcus epidermidis (ATCC14990) and S. aureus (ATCC25923). Gram-negative bacteria: Enterobacter cloacae (ATCC13047), Escherischia coli (ATCC25922), Klebsiella oxytoca 
(ATCC8724), K. pneumonia (ATCC13882), Proteus mirabilis (ATCC7002) and Pseudomonas aeruginosa (ATCC27853) were cultured overnight in Mueller-Hinton broth at $25{ }^{\circ} \mathrm{C}$; Merck Chemicals, SA). The turbidity of the culture solutions were adjusted to match a $0.5 \mathrm{McFarland}$ standard within 15 minutes prior to antibacterial testing.

\section{Antibacterial Testing}

Antibacterial studies were initiated by the disc diffusion method as a means to evaluate the most potent alkyl and aryl pyrimido[1,2-a]benzimidazole derivatives. In-vitro antibacterial screening was carried out using a filter-paper disc-agar diffusion procedure [6]. Sterile filter-paper blank discs $(6 \mathrm{~mm})$ were impregnated with $1 \mathrm{mg}$ of compounds $\mathbf{1 a}, \mathbf{1 b}$, $\mathbf{2 a}, \mathbf{2 b}$, and 2c. The disks were air-dried while Muller-Hinton agar plates (prepared earlier) were inoculated with the test bacteria using a sterile cotton swab. Impregnated filter-paper discs (loaded with the same masses of the test compounds) were then placed on the surface of agar plates to allow for the diffusion of the compounds into the agar, the plates were incubated at $37{ }^{\circ} \mathrm{C}$ for $16 \mathrm{hrs}$.

Minimum inhibitory concentrations (MIC) of all the strains were determined by the broth microdilution assay [7]. The test compounds were accurately weighed and dissolved in DMSO to yield $512 \mu \mathrm{g} / \mathrm{ml}$. The dissolved compounds were then serially diluted in Mueller-Hinton broth till the lowest concentration of $1 \mu \mathrm{g} / \mathrm{ml}$. All dilutions were tested five-fold against each bacterial strain. $100 \mu 1$ of the bacterial suspension was mixed with $100 \mu \mathrm{l}$ of pre-diluted test compound in a 96 microwell plate and left to incubate overnight at $37^{\circ} \mathrm{C}$. $10 \mu \mathrm{l}$ of a $0.02 \%(\mathrm{w} / \mathrm{v})$ tetrazolium sodium solution was added to each well and the plates were re-incubated for 2 hours. Visual change of the solution from blue to pink indicated that the bacteria were still alive. MIC was determined as the minimum concentration of compound where no colour change could be observed. The MIC of all strains tested were compared to two reference antibiotics (nalidixic acid and streptomycin sulphate). This was due to the fact that whilst streptomycin is a broad based antibiotic, nalidixic acid has been shown to be exclusively active against Gram-negative bacteria [8].

\section{Synthesis of Aryl And Alkyl Pyrimido [1,2-A] Benzimidazole Derivatives [9]}

2-amino-4-phenyl pyrimido[1,2-a]benzimidazoles were prepared by the Michael addition of 2-aminobenzimidazoles on phenylacetylene nitriles and acetylenic nitriles respectively, followed by cyclisation to give compounds $\mathbf{1 a}$ and $\mathbf{1 b}$.

2-Amino-4-phenylpyrimido[1,2-a]benzimidazole (1a). Yield $1.97 \mathrm{~g}(76 \%)$ colourless crystals (DMSO), mp $300^{\circ} \mathrm{C}$; IR: v/cm-1 3440, 3303 (NH2), 3054 (aryl. C-H), $1653(\mathrm{C}=\mathrm{N}), 1600$ $(\mathrm{C}=\mathrm{C}), 1533$ (NH2 def). NMR data: $\delta \mathrm{H}(\mathrm{DMSO}-\mathrm{d} 6) 6.13(1 \mathrm{H}$, 6-H), 6.15 (1H, s, 3-H), 6.75 (1H, m, 7-H), 7.15 (1H, m, 8-H), $7.50(1 \mathrm{H}, \mathrm{m}, 9-\mathrm{H}), 7.40(2 \mathrm{H}, \mathrm{s}, \mathrm{NH} 2$ deuterium exchangeable), 7.63-7.69 (5H, m, Ph). $\delta \mathrm{C}$ (DMSO-d6) 99.6 (C-3), 112.5 (C-6), 117.6 (C-9), 118.7 (C-8), 123.9 (C-7), 127.7 (C-5a), 128.5 (Ph-C3, C5), 129.3 (Ph-C2, C6), 130.8 (Ph- C4), 132.6 (Ph-C1), 144.7 (C-9a), 147.7 (C-4), 153.6 (C-2), 160.5 (C-10a). MS: m/z (\%) = $260(\mathrm{M}+, 100), 259$ (23), 220 (18), 133 (8), 116
(4), 104 (5), 90 (9), 77 (5). Anal. Calcd. for C16H12N4: C, 73.85; H, 4.61; N, 21.54. Found: C, 73.41; H, 4.58; N, 21.22

2-Amino-7,8-dimethyl-4-phenylpyrimido[1,2-a]benzimidazole (1b). Yield 2.50g (87\%), colourless crystals (DMSO), mp $300^{\circ} \mathrm{C}$; IR: $v / \mathrm{cm}-1$ 3442, $3301(\mathrm{NH} 2), 3050$ (aryl C-H), 1650 $(\mathrm{C}=\mathrm{N}), 1600 \quad(\mathrm{C}=\mathrm{C}), 1529 \quad(\mathrm{NH} 2 \mathrm{def}) . \quad \mathrm{NMR}$ data: $\delta \mathrm{H}$ (DMSO-d6) 1.95 (3H, s, 7-CH3), 2.25 (3H, s, 8-CH3), 5.87 $(1 \mathrm{H}, \mathrm{s}, 6-\mathrm{H}), 6.10(1 \mathrm{H}, \mathrm{s}, 3-\mathrm{H}), 7.27(2 \mathrm{H}, \mathrm{s}, \mathrm{NH} 2$ deuterium exchangeable), $7.65(1 \mathrm{H}, \mathrm{s}, 9-\mathrm{H}), 7.59-7.70(5 \mathrm{H}, \mathrm{m}, \mathrm{Ph}) . \delta \mathrm{C}$ (DMSO-d6) 19.84 (8-CH3), 20.06 (7-CH3), 98.91 (C-3), 112.94 (C-6), 117.94 (C-9), 126.29 (C-7), 126.51 (C-8), 128.39 (Ph-C3, C5), 129.06 (Ph- C2, C6), 130.50 (Ph-C4), 132.03 (C-5a), 132.61 (Ph-C1), 143.13 (C-9a), 147.50 (C-4), 153.50 (C-2), 161.5 (C-10a). MS: m/z (\%) = $288(\mathrm{M}+, 100), 287$ (34), 273 (15), 160 (6), 144 (7), 136 (6), 128 (5). Anal. Calcd. for C18H16N4: C, 75.00; H, 5.56; N, 19.44. Found: C, 74.86; H, $5.53 ; \mathrm{N}, 19.15$.

\section{E. Synthesis of alkyl pyrimido[1,2-a]benzimidazole derivatives [10]}

2-amino-4-(1-methylpropyl)pyrimido[1,2-a]benzimidazole was prepared from the reaction between 4-methylhexa-2,3-dienenitrile and 2-amino-benzimidazole in $\mathrm{N}, \mathrm{N}$-dimethylformamide under reflux conditions for 4 days. 2-amino-4-(1-methylpropyl)pyrimido[1, 2-a]benzimidazole (2a). Yield (4.30g, $90 \%)$, mp $258{ }^{\circ} \mathrm{C}$, IR: v/cm-1 $3300\left(\mathrm{NH}_{2}\right)$, 3150 (aryl. C-H), $1640(\mathrm{C}=\mathrm{N}), 1640(\mathrm{C}=\mathrm{C}), 1560\left(\mathrm{NH}_{2} \mathrm{def}\right)$. NMR data: ${ }^{1} \mathrm{H}$ NMR (DMSO-d 6$) \delta 3.52-3.66(7 \mathrm{H}, \mathrm{m}, 12-\mathrm{H})$; $6.22(1 \mathrm{H}, \mathrm{s}, 3-\mathrm{H}) ; 7.12(1 \mathrm{H}, \mathrm{dd}, 7-\mathrm{H}) ; 7.30(1 \mathrm{H}, \mathrm{dd}, 8-\mathrm{H})$; 7.26(2H, s, $\mathrm{NH}_{2}$ deuterium exchangable); 7.56(1H, d, 9-H); 7.88(1H, d, 6-H). 13C (DMSO-d 6 ) $\delta 34.8(\mathrm{C}-12), 94.8(\mathrm{C}-3)$, 113.7(C-7),117.3(C-8), 119.1(C-6), 129.6, (C-9) 144.6(C-4), 153.7(C-5a), 155.3(C-9a), 160.6(C-10a). MS: $\mathrm{m} / \mathrm{z}(\%)=$ 240(M+, 100), 255 (15), 221 (18), 211 (46), 209(21), 156 (15), 133 (11), 129 (10), 106(1), 90 (22), 44 (2), 41 (11). Anal. Calcd. for $\mathrm{C}_{14} \mathrm{H}_{16} \mathrm{~N}_{4}$ : C, 70.00; H, 6.67; N, 23.33. Found: C, 69.97; H, $6.60 ; \mathrm{N}, 23.36$.

2-amino-4-(1-ethylpropyl)-7,8-dimethylpyrimido[1,2-a]benzim idazole (2b). Yield (92 \%) white crystals. mp $307{ }^{\circ} \mathrm{C}$, IR: v/cm-1 3450, $3250(\mathrm{NH} 2), 1650(\mathrm{C}=\mathrm{N}), 1610(\mathrm{C}=\mathrm{C}), 1560$ $\left.\left(\mathrm{NH}_{2} \text { def). NMR data: }{ }^{1} \mathrm{H} \text { NMR (DMSO-d }\right)_{6}\right) 2.35(3 \mathrm{H}, \mathrm{s}$, $\left.7-\mathrm{CH}_{3}\right) ; 2.35\left(3 \mathrm{H}, \mathrm{s}, 8-\mathrm{CH}_{3}\right) ; 3.50-3.66(\mathrm{~m}, 12-\mathrm{H}) ; 6.25(2 \mathrm{H}, \mathrm{s}$, $3-\mathrm{H})$; 7.30(1H, s, 9-H), 7.70(1H, s, 6-H) 13C (DMSO-d6) $\delta$ 19.7 $\left(\mathrm{C}-7-\mathrm{CH}_{3}\right), \quad 19.9\left(\mathrm{C}-8-\mathrm{CH}_{3}\right), \quad 40.9(\mathrm{C}-12), \quad 96.2(\mathrm{C}-3)$, 114.4(C-6), 116.4(C-9), 125.6(C-7), 128.4(C-8), 132.9(C-2), 139.4(C-4), 152.0(C-5a), 153.5(C-9a), 160.6(C-10a). MS: m/z (\%) = 282(M+, 100), 253 (30), 238 (18), 237 (30), 223(11), 106 (2), 91 (10), 45 (5), 41(11), 36 (13), 29 (26), 27 (13). Anal. Calcd. for C17H22N4: C, 72.34; H, 7.80; N, 19.86. Found: C, 72.21; H, 7.86; N, 20.01.

2-Amino-4-(1,3-dimethylbutyl)pyrimido[1,2-a]benzimidazole (2c). Yield (75\%) white crystals mp $279{ }^{\circ} \mathrm{C}$ IR: v/cm-1 3350, $3150\left(\mathrm{NH}_{2}\right), 1650(\mathrm{C}=\mathrm{N}), 1575(\mathrm{C}=\mathrm{C}), 1525$ (NH2 def). NMR data: ${ }^{1} \mathrm{H}\left(\mathrm{DMSO}-\mathrm{d}_{6}\right) \delta 2.48-2.51(\mathrm{~m}, 12-\mathrm{H}) ; 6.21(1 \mathrm{H}, \mathrm{s}, 3-\mathrm{H})$; 7.13(1H, dd, 7-H); 7.22(s, NH2); 7.30(dd, 1H, 8-H), 7.54(1H, $\mathrm{d}, 9-\mathrm{H}), \quad 7.81(1 \mathrm{H}, \mathrm{d}, 6-\mathrm{H}){ }^{13} \mathrm{C}\left(\mathrm{DMSO}_{6}\right) \quad \delta \quad 31.7$ (C-12), 94.9(C-3), 113.9(C-7), 117.7(C-8), 119.4(C-6), 127.9(C-9), 144.8(C-4), 153.8(C-5a), 156.1(C-9a), 160.9(C-10a). MS: m/z 
$(\%)=268(\mathrm{M}+, 100), 267(4), 225(4), 223(3), 213(13), 212$ (89), 211 (39), $210(6), 209(16), 198(4), 197(7), 184(6), 172$ (5), 170 (4), 156 (7), 134(7), 133 (16), 105 (6), 92 (3), 90 (8), 83 (3), 57 (4), 44(20), 43 (5), 41 (8), 40 (11), 39 (11). Anal. Calcd. for $\mathrm{C} 16 \mathrm{H} 20 \mathrm{~N} 4$ : $\mathrm{C}, 71.61 ; \mathrm{H}, 7.51 ; \mathrm{N}, 20.87$. Found: $\mathrm{C}, 71.63$; $\mathrm{H}, 7.45 ; \mathrm{N}, 20.64$.

\section{RESULTS AND DISCUSSION}

This series of derivatives was evaluated with the sole intention of probing its SAR profiles against clinically significant bacterial pathogens. Although the compounds had been earlier evaluated against Staphylococcus aureus and Mycobacterium ranae [10], it was not apparent whether the compounds would be active against a range of other medically important bacteria. Table 1 summarizes the results of compounds $\mathbf{1 a}, \mathbf{1 b}, \mathbf{2 a}, \mathbf{2 b}$ and $\mathbf{2 c}$ against the test bacteria. The compounds were assessed for antibacterial activity and only compound $\mathbf{2 b}$ possessed potent activities (compared to nalidixic acid) against 4 of the six gram-negative bacteria profiled (Enterobacter cloacae, Escherichia coli, Pseudomonas aeruginosa and Proteus mirabilis). Moderate activities (in relation to streptomycin) were observed for the 5 gram-positive bacteria (Staphylococcus aureus, Staphylococcus epidermidis, Bacillus cereus, Bacillus subtilis and Enterococcus faecalis). The remaining compounds were inactive.

Table I: MIC OF PYRIMIDOBENZIMIDAZOLES

\begin{tabular}{|c|c|c|c|c|}
\hline Bacterial strain & Zone of inhibition & 2b MIC $(\mu \mathrm{g} / \mathrm{ml})$ & Streptomycin $(\mu \mathrm{g} / \mathrm{ml})$ & Nalidixic acid $(\mu \mathrm{g} / \mathrm{ml})$ \\
\hline Enterococcus faecalis & 21.0 & 64 & 128 & \\
\hline Escherichia coli & 18.3 & 4 & & $>512$ \\
\hline Klebsiella oxytoca & 18.8 & 512 & & 8 \\
\hline Klebsiella pneumoniae & 18.8 & 64 & & 64 \\
\hline Pseudomonas aeruginosa & 11.5 & 2 & & $>512$ \\
\hline Proteus mirabilis & 13.5 & 2 & & 32 \\
\hline Staphylococcus aureus & 21.5 & 32 & 8 & \\
\hline Staphylococcus epidermidis & 22.8 & 16 & 8 & \\
\hline
\end{tabular}

Although compounds $\mathbf{2 a}$ and $\mathbf{2 b}$ were initially tested against Mycobacterium ranae and Staphylococcus aureus and found to possess minor microbial activity [10], it is surprising to observe (Table I) that in this study, S. aureus and M. smegmatis were resistant to 2a. This conflict could be clarified by re-evaluating 2a against $M$. ranae, which we do not have in our possession. Another likelihood for the contradictory antimicrobial observations could arise from the fact that the $M$. ranae used by Asobo et al may have possibly been a Mycobacterium fortuitum, a fast growing strain having somewhat different growth patterns compared to $M$. smegmatis. Although this requires further studying, the differences in growth patterns could account for the observed conflicts in MIC's. In an in-depth study where it was shown that a vast number of fast growing Mycobacteria were initially incorrectly characterised, and in particular M. fortuitum was erroneously used to describe $M$. ranae [11].<smiles>[R]c1cc2nc3nc(N)cc(-c4ccccc4)n3c2cc1[R]</smiles><smiles>[R]c1cc2nc3nc(N)cc(C([R3])[R])n3c2cc1[R]</smiles>

1a: $\mathrm{R}_{1}=\mathrm{R}_{2}=\mathrm{H}$ 1b: $\mathrm{R}_{1}=\mathrm{R}_{2}=\mathrm{CH}_{3}$

$$
\begin{aligned}
& \text { 2a: } \mathrm{R}_{1}=\mathrm{R}_{2}=\mathrm{H}, \mathrm{R}_{3}=\mathrm{Me}, \mathrm{R}_{4}=\mathrm{Et} \\
& \text { 2b: } \mathrm{R}_{1}=\mathrm{R}_{2}=\mathrm{Me}, \mathrm{R}_{3}=\mathrm{R}_{4}=\mathrm{Et} \\
& \text { 2c: } \mathrm{R}_{1}=\mathrm{R}_{2}=\mathrm{H}, \mathrm{R}_{3}=\mathrm{Me}, \mathrm{R}_{4}=i-\mathrm{Bu}
\end{aligned}
$$

Fig. 1. Synthesis of 2-amino-4-phenylpyrimido[1, 2-a]benzimidazoles

\section{CONCLUSION}

In an attempt to establish a platform and utility of benzimidazoles as potent antimicrobials, pyrimido[1,2-a]benzimidazole derivatives were resynthesized following published procedure and evaluated against some medically important Gram-positive and Gram-negative bacteria. The results revealed that only one compound (2b) with activating groups attached to the benzimidazole ring displayed strong antimicrobial activities and that alkyl and phenyl substituents on the pyrimidine ring did not significantly contribute to the bioactive properties of the test compounds. Compound $\mathbf{2 b}$ may thus serve as a foundation for the synthesis of more potent antimicrobials. It would also be interesting to evaluate bioactive profiles of $\mathbf{1 a}, \mathbf{1 b}, \mathbf{2} \mathbf{a}$ and $\mathbf{2 c}$ encompassing a diverse group of electron donating and withdrawing groups around the benzimidazole ring as it seems this is a crucial pharmacophore.

\section{REFERENCES}

[1] E. M. Streicher, B. Müller, V. Chihota, C. Mlambo, M. Tait, M. Pillay, A. Trollip, K. G. P. Hoek, A. Frederick, F. A. Sirgel, N. C. G. van Pittius, P. D. van Helden, T. . Victor, and R. . Warren, "Emergence and treatment of multidrug resistant (MDR) and extensively drug-resistant (XDR) tuberculosis in South Africa," Infect. Genet. Evol., vol. 12, pp. 686-694, 2012.

[2] L. Cantas, S. Q. A. Shah, L. M. Cavaco, C. M. Manaia, F. Walsh, M. Popowska, H. Garelick, H. Bürgmann, and H. Sørum, "A brief multi-disciplinary review on antimicrobial resistance in medicine and its linkage to the global environmental microbiota.," Front Microbiol, vol. 14, no. 9, pp. 96-96, 213AD.

[3] Y. Bansal and O. Silakari, "The therapeutic journey of benzimidazoles: a 
review.," Bioorg. Med. Chem., vol. 20, no. 21, pp. 6208-36, Nov. 2012.

[4] M. R. Shaaban, T. S. Saleh, A. S. Mayhoub, A. Mansour, and A. M. Farag, "Bioorganic \& Medicinal Chemistry Synthesis and analgesic / anti-inflammatory evaluation of fused heterocyclic ring systems incorporating phenylsulfonyl moiety," Bioorg. Med. Chem., vol. 16, pp. 6344-6352, 2008.

[5] P. Mehta, P. Davadra, N. Shah, and H. Joshi, "Synthesis and antimicrobial activity of some new imidazolinone derivatives containing benzimidazole," Int. Lett. Chem. Phys. Astron., vol. 10, pp. 74-80, 2014.

[6] M. Othman, H. S. Loh, C. Wiart, T. J. Khoo, K. H. Lim, and K. N. Ting, "Optimal methods for evaluating antimicrobial activities from plant extracts," J. Microbiol. Methods, vol. 84, no. 2, pp. 161-166, 2011.

[7] J. M. Andrews, "Determination of minimum inhibitory concentrations," J. Antimicrob. Chemother., vol. 48 Suppl 1, pp. 5-16, 2001.

[8] A. Dalhoff, "In vitro activities of quinolones," Expert Opin. Investig. Drugs, vol. 8, pp. 123-137, 1999.

[9] H. Wahe, P. F. Asobo, R. A. Cherkasov, A. E. Nkengfack, P. F. Folofoc, Z. T. Fomum, and D. Döpp, "Heterocycles of biological importance . Part 6. The formation of novel biologically active pyrimido $[1,2-$ a $]$ benzimid- azoles from electron deficient alkynes and 2-aminobenzimidazoles," Arkivoc, vol. 2003, no. xiv, pp. 170-177, 2003.

[10] P. Forche Asobo, H. Wahe, J. T. Mbafor, A. E. Nkengfack, Z. T. Fomum, E. F. Sopbue, and D. Döpp, "Heterocycles of biological importance. Part 5. The formation of novel biologically active pyrimido[1,2-a]benzimidazoles from allenic nitriles and aminobenzimidazoles," J. Chem. Soc. Perkin Trans. 1, pp. 457-461, 2001.

[11] J. M. Grange and J. L. Stanford, "Re-evaluation of Mycobacterium fortuitum," Int. J. Syst. Bacteriol., vol. 24, no. 3, pp. 320-329, 1974. 